13,14

\title{
Эффекты микрофазового разделения и корреляции типа плотность-плотность в аморфных полимерных пленках
}

\author{
(C) Д.В. Новиков \\ Санкт-Петербургский государственный лесотехнический университет им. С.М. Кирова, \\ Санкт-Петербург, Россия \\ E-mail: dvnovikov65@mail.ru
}

Поступила в Редакцию 1 сентября 2020 г.

В окончательной редакции 1 сентября 2020 г.

Принята к публикации 13 сентября 2020 г.

По данным электронной микроскопии в субмикронном и микронном масштабных диапазонах изучена топология флуктуаций плотности на поверхности тонких аморфных пленок, полученных из растворов некоторых гибкоцепных полимеров. Показано, что с ростом исходной концентрации растворов в пленках усиливаются эффекты микрофазового разделения за счет самоорганизации агрегатов (кластеров) макромолекул: увеличиваются анизотропия, дальний порядок и корреляционная длина $\xi$ флуктуаций плотности. Самоорганизация завершается образованием бесконечного кластера частиц, периодически-неоднородного по плотности и занимающего $\sim 30 \%$ поверхности пленок. Корреляционная функция типа плотность-плотность такого кластера на масштабе $\sim \xi$ имеет универсальный вид, не зависящий от состава и молекулярной массы полимера.

Ключевые слова: тонкие полимерные пленки, электронная микроскопия, микрофлуктуации плотности, микрофазовое разделение.

DOI: 10.21883/FTT.2021.01.50413.180

\section{1. Введение}

К настоящему времени достаточно подробно изучены полимерные материалы с пространственно-модулированной (периодической) надмолекулярной структурой, образующейся за счет микрофазового разделения. Например, можно отметить пленочные материалы на основе блок-сополимеров [1,2], а также полимерных смесей в состоянии спинодального распада $[3,4]$.

Особый случай микрофазового разделения, названный в работе [2] псевдофазовым, реализуется в аморфных пленках, полученных из концентрированных растворов гибкоцепных полимеров. В таких пленках также обнаруживаются периодические флуктуации плотности субмикронного и микронного масштаба [2]. Крупномасштабные флуктуации плотности, корреляционная длина которых существенно превышает гидродинамический радиус $R_{g}$ макромолекулярного клубка в растворе, объясняются моделью ССА кластер-кластерной агрегации. Эта модель учитывает образование ассоциатов (кластеров) макромолекул в растворе, их необратимую агрегацию при испарении растворителя и формирование физической сетки зацеплений цепей в пленке [5,6]. Кластеры обладают низкой диффузионной подвижностью, поэтому построенная из них сетка зацеплений имеет плотный каркас и микрообласти с меньшей локальной плотностью упаковки частиц [7]. Подобная структура свойственна полимерным студням с так называемым незавершенным фазовым разделением [8].

Образование периодически неоднородной микроструктуры полимерных пленок свидетельствует о самоорга- низации агрегатов макромолекул, управляемой величиной $c$ исходной концентрации раствора. Ранее автором с сотрудниками была исследована топология флуктуаций плотности на поверхности тонких аморфных пленок, полученных из растворов гибкоцепных полимеров атактического полистирола (at-PS) [5,6] и полиэфиримида (PEI) [2,9] при вариации параметра $c$. Методом просвечивающей электронной микроскопии (ТЕМ) было показано, что с ростом параметра $c$ усиливается структурная неоднородность пленок вследствие увеличения как относительной величины микрофлуктуаций локальной плотности, так и пространственной доли областей поверхности с менее плотной упаковкой макромолекул $[5,6,9]$. При этом рост термодинамической энтропии компенсируется за счет возникновения дальнего порядка в пространственном распределении флуктуаций плотности [2].

В работах $[5,6,9]$ были приведены радиальные функции $g(R)$ распределения флуктуаций плотности на поверхности пленок. Однако эти функции были рассчитаны в достаточно узких диапазонах шкалы масштаба, что исключало проведение сравнительного анализа. В продолжении работ $[5,6,9]$ в настоящей работе получены более точные корреляционные функции $g(R)$, изучено их взаимное соответствие для ряда тонких аморфных пленок полимеров различного химического состава и молекулярной массы, а также исследована трансформация текстуры поверхности в зависимости от концентрационного режима формирования образцов. Цель работы объяснение возникновения пространственно-модулированных (периодических) микрофлуктуаций плотности 


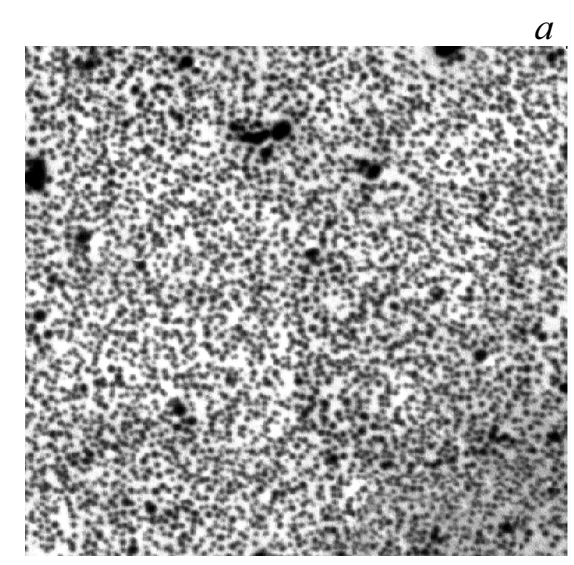

$0.5 \mu \mathrm{m}$

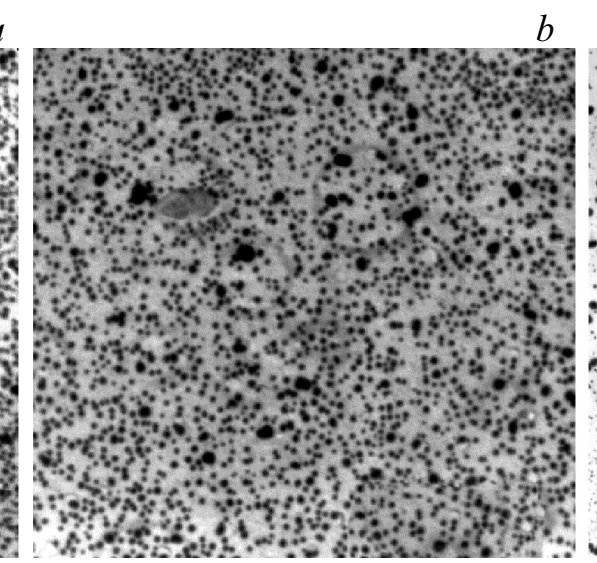

$0.5 \mu \mathrm{m}$

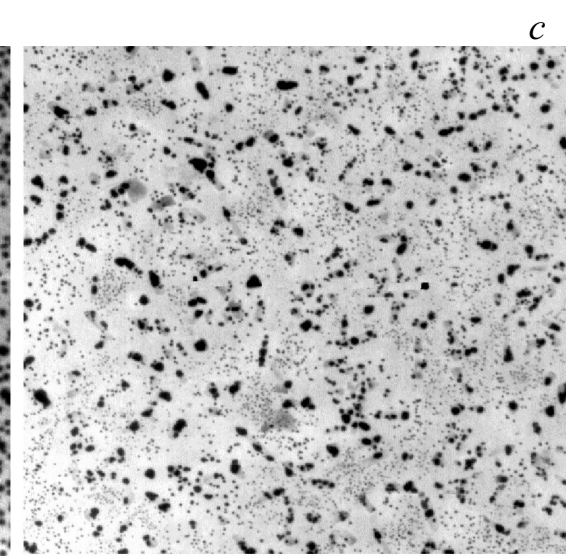

$2.5 \mu \mathrm{m}$

Рис. 1. Электронные микрофотографии декорированной золотом поверхности пленок at-PS, полученных из растворов полимера в Dek при $c=0.4(a), c^{*}=0.56(b)$ и $c=0.9 \mathrm{~g} \cdot \mathrm{dl}^{-1}(c)$.

в аморфных полимерных пленках исходя из представлений о самоорганизации агрегатов макромолекул в концентрированном растворе при пленкообразовании.

\section{2. Объекты и методы исследования}

В работе использовались гибкоцепные полимеры: атактический полистирол (at-PS) со среднечисленной молекулярной массой $M_{n}=9 \cdot 10^{6}$ и узким молекулярно-массовым распределением [5]; полиэфиримидполи $\left\{4,4^{\prime}\right.$-бис $\left[\left(4^{\prime \prime}-\mathrm{N}\right.\right.$-фенокси $)$ дифенилсульфон] имид $1,3-$ бис $\left(3^{\prime}, 4\right.$-дикарбоксифенокси)бензола $\}$ (PEI) со средневесовой молекулярной массой $M_{w}=6 \cdot 10^{5} \quad[2]$; полиимид (PI), полученный на основе диангидрида $3,4,3^{\prime}, 4^{\prime}$-тетракарбоксидифенилоксида и $4,4^{\prime}$-оксидианилина со значением $M_{n}=5 \cdot 10^{5}$ [10]. Аморфные пленки толщиной $15-25 \mu \mathrm{m}$ формировались на стеклянной подложке из растворов at-PS в декалине (Dek) при температуре $T=313 \mathrm{~K}$ (на $12 \mathrm{~K}$ выше $\theta$-точки) и хлороформе (Chl) при $T=298 \mathrm{~K}$, PEI в N-метилпирролидоне (NMP) при $T=298 \mathrm{~K}$ и форполимера PI (полиамидокислоты) в Chl при $T=298 \mathrm{~K}$ с последующей термической имидизацией образца. Концентрация c растворов варьировалась относительно порогового значения $c^{*}$ [5], отвечающего образованию непрерывной флуктуационной сетки зацеплений макромолекул.

Для анализа топологической структуры поверхности пленок использовалась ТЕМ-методика декорирования золотом „химических меток“ хемосорбированного брома. Данная методика, применимая к аморфным и мезоморфным полимерам [11], основана на статистическом анализе межчастичных расстояний в ансамбле декорирующих наночастиц. Такой анализ позволяет с высоким разрешением исследовать топологию флуктуаций плотности упаковки макромолекул в субмикронном и микронном диапазонах шкалы масштаба. Препарирование образцов для ТЕМ осуществлялось путем предварительной активации „воздушной“ поверхности пленок молекулярным бромом [5,11] с последующим вакуумным термическим напылением золота. Наночастицы золота отделялись от поверхности с помощью опорной угольной реплики и изучались в просвечивающем электронном микроскопе EMV100L. Двумерные изображения декорированной поверхности подвергались компьютерной оцифровке и включали при этом не менее 5000 частиц.

Изучение пространственных корреляций типа плотность-плотность на поверхности образцов проводилось с использованием так называемых „крупнозернистых“ радиальных функций $g(R)$ распределения декорирующих наночастиц золота. Для получения этих функций использовалось пошаговое сканирование плотности распределения частиц на двумерных изображениях поверхности с шагом, соответствующим наиболее вероятному расстоянию $r$ между частицами [2]. Корреляционная длина $\xi$ определялась по положению особых точек функций $g(R)$.

Индикатрисы плотности $\rho$ распределения наночастиц золота рассчитывались при усреднении по прямоугольникам $2 r \times \xi$ с центром в частицах и изменении угла $\theta$ ориентации прямоугольников [2].

\section{3. Результаты и их обсуждение}

Электронные микрофотографии декорирующих наночастиц золота на поверхности полимерных пленок свидетельствуют об усилении эффектов микрофазового разделения в образцах с ростом исходной концентрации $c$ пленкообразующего раствора (рис. 1). На это указывает увеличение как ширины распределения частиц золота по размеру, так и пространственной доли областей поверхности, не занятых частицами. На поверхности пленок, полученных из концентрированных растворов полимеров, размеры некоторых частиц золота различа- 

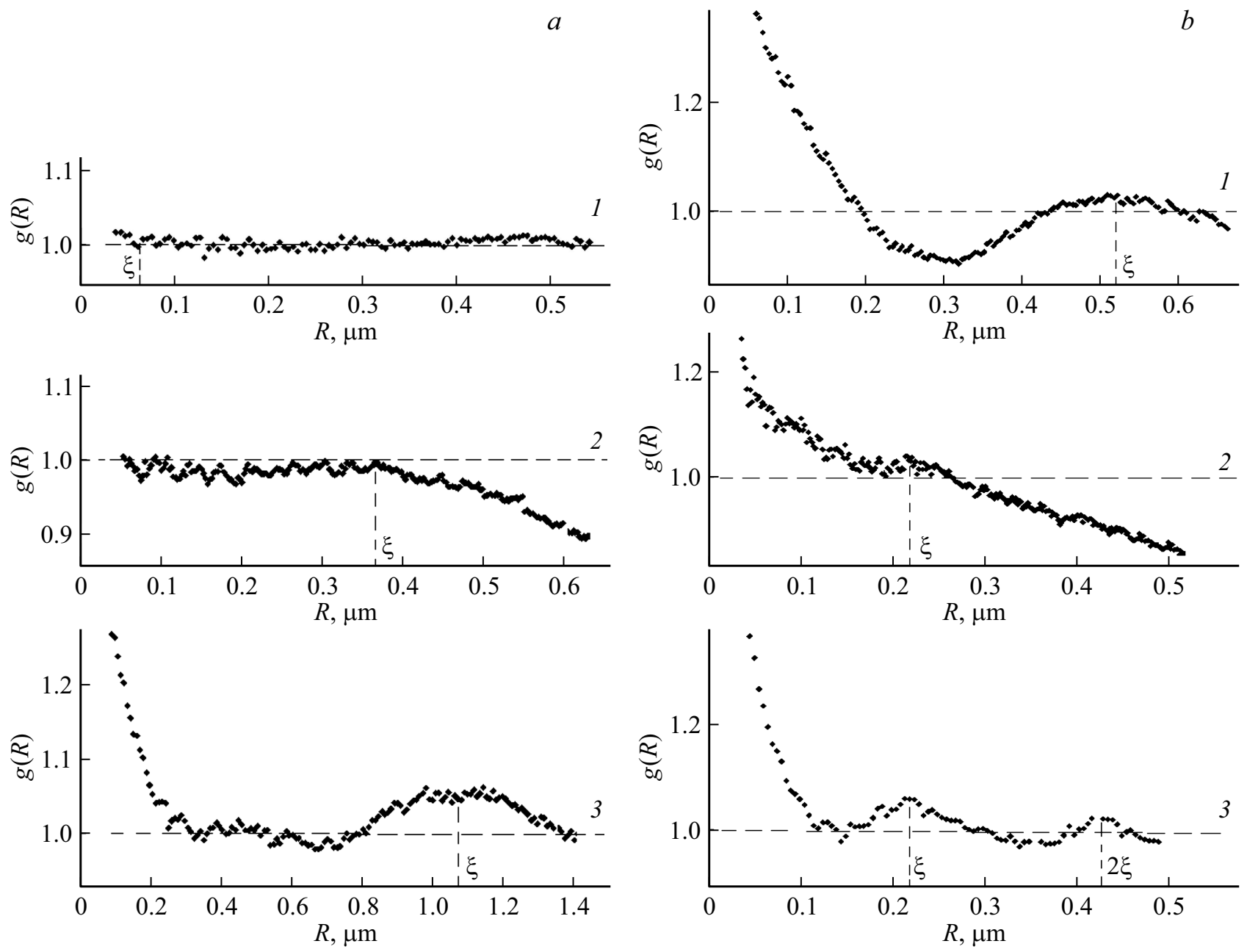

Рис. 2. Радиальные функции $g(R)$ распределения микрофлуктуаций повышенной плотности на поверхности пленок, полученных из растворов at-PS в Dek $(a): c=0.4(1), c^{*}=0.56(2), c=0.9 \mathrm{~g} \cdot \mathrm{dl}^{-1}(3)$ и пленок, полученных из растворов PEI в NMP $(b)$ : $c=6(1), c^{*}=14(2), c=20 \mathrm{~g} \cdot \mathrm{dl}^{-1}(3)$.

ются более чем на порядок (рис. 1,c). При этом для изученных полимеров — at-PS, PEI [9] и PI [10] — изображения декорированной золотом поверхности подобны друг другу.

Наночастицы золота размером $\sim 40 \mathrm{~nm}$ отображают флуктуации повышенной плотности упаковки макромолекул [12]. Доля пространства [9], занятая плотными агрегатами макромолекул, с ростом параметра $c$ уменьшается и приближается к величине $\sim 0.3$. При этом плотные участки непрерывно заполняют собой поверхность, образуя единый бесконечный кластер. Крупные частицы золота, размер которых превышает $100 \mathrm{~nm}$, соответствуют менее плотным областям поверхности [9]. Общая площадь участков поверхности, приходящихся на крупные частицы, при увеличении $c$ возрастает.

Особенности пространственных корреляций типа плотность-плотность на поверхности полимерных пленок предопределяются концентрационным режимом формирования образцов. На рис. $2, a, b$ представлены радиальные функции $g(R)$ распределения локальной плот- ности скоплений декорирующих наночастиц золота для пленок at-PS и PEI, полученных при вариации исходной концентрации $c$ растворов полимеров: в случае $c<c^{*}$ (кривая 1), $c \sim c^{*}$ (кривая 2) и $c>c^{*}$ (кривая 3).

Корреляционная длина $\xi$ флуктуаций плотности упаковки макромолекул в пленках at-PS, полученных из растворов полимера в Dek (рис. 2,a) и Chl $[5,6]$, увеличивается с ростом параметра $c$ и в случае Dek при $c \sim 1.5 c^{*}=0.9 \mathrm{~g} \cdot \mathrm{dl}^{-1}$ (рис. 2, $a$, кривая 3) становится более чем на порядок больше радиуса $R_{g}$ клубка [5].

В растворах PEI за счет сильных межмолекулярных взаимодействий [13] ассоциация макромолекул более выражена чем в растворах at-PS, что подтверждается сравнительными данными о степени агрегации частиц в кластерах [5,9]. По этой причине в пленках PEI не прослеживается зависимость $\xi$ от параметра $c$. Однако и в данном случае при $c \sim 1.5 c^{*}=20 \mathrm{~g} \cdot \mathrm{dl}^{-1}$ (рис. $2, b$, кривая 3 ) величина $\xi$ более чем на порядок превышает радиус $R_{g}$ клубка, а корреляции типа плотность-плотность распространяются на расстояние $2 \xi \sim 0.5 \mu \mathrm{m}$. 
На поверхности пленок, полученных из концентрированных растворов полимеров (например, при $c \sim 1.5 c^{*}$ ), наблюдается дальний порядок чередования скоплений наночастиц золота (рис. 2, $a, b$; кривая 3). Возникновение дальнего порядка свидетельствует о микрофазовом разделении в образцах [2]. Период чередования флуктуаций плотности соответствует положению максимума функций $g(R)$ и равен корреляционной длине $\xi$.

Формирование периодически-неоднородного по плотности бесконечного кластера, построенного из агрегатов макромолекул, происходит в результате структурной самоорганизации [14] системы полимер-растворитель или неравновесного перехода упорядочения при пленкообразовании. Для такого перехода складываются необходимые условия: многоуровневая (кластерная) структура раствора и ограниченное число степеней свободы кластеров, необратимый характер формирования полимерной пленки.

Важным признаком структурной самоорганизации является фрактализация $[15,16]$ поверхности пленок, полученных в режиме $c \sim c^{*}$, т.е. в условиях, предшествующих по шкале $c$ образованию периодических микрофлуктуаций плотности (рис. 2, $a, b$, кривая 2). В таких пленках на масштабе $R>\xi$ формируется масштабноинвариантная [17] (фрактальная) структура бесконечного кластера плотноупакованных макромолекул. На данном масштабе функции $g(R)$ спадают по степенному закону: $g(R) \propto R^{D-2}$, причем значение фрактальной размерности $D$ составляет $1.8 \pm 0.02$ в двумерном отображении поверхности и близко к величине $1.78 \pm 0.03$ для ССА-модели случайной кластер-кластерной агрегации [18].

На рис. 3, $a, b$ представлены индикатрисы относительной локальной плотности $\rho$ распределения наночастиц золота на поверхности образцов. Полученные угловые зависимости $\rho(\theta)$ позволяют определить характер текстуры поверхности пленок.

Пространственное распределение плотности полимера на поверхности пленок at-PS, полученных при $c<c^{*}$ и $c \sim c^{*}$, практически изотропно (рис. $3, a$, кривые 1 и 2 соответственно). Поверхность пленки, сформированной из концентрированного раствора полимера, имеет слабовыраженную одноосную текстуру (рис. 2, a, кривая 3).

В случае PEI все изученные образцы пленок характеризуются одноосной текстурой поверхности (рис. 3,b). Это согласуется с данными работы [19], в которой было зафиксировано спонтанное двойное лучепреломление в пленках PEI. Обнаруженный эффект объяснялся возникновением слабого ориентационного порядка фрагментов макромолекул вблизи поверхности пленок. С ростом параметра $c$ в области $c>c^{*}$ анизотропия плотности увеличивается, и при $c \sim 1.5 c^{*}$ локальные плотности распределения декорирующих наночастиц золота вдоль и поперек оси текстуры отличаются на $\sim 8 \%$ (рис. $3, b$, кривая 3). Важно отметить, что наиболее однородное пространственное распределение флуктуаций плотности соответствует пленке PEI, сформированной из раствора
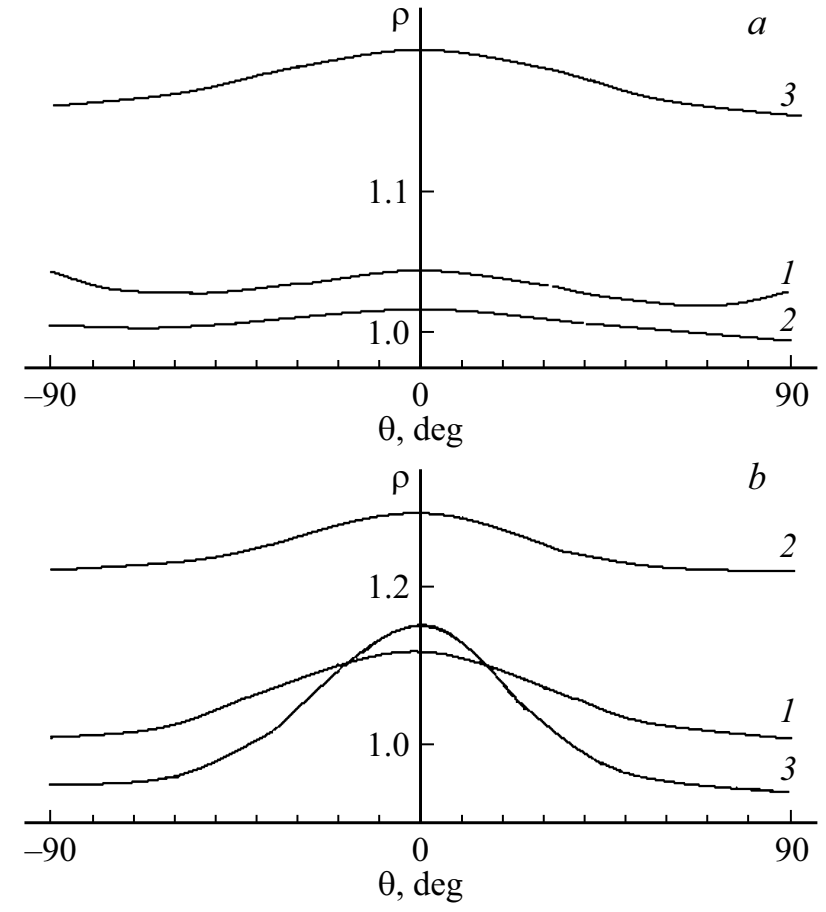

Рис. 3. Индикатрисы относительной (по отношению к средней по поверхности) плотности $\rho$ распределения наночастиц золота на поверхности пленок, полученных из растворов at-PS в Dek $(a): c=0.4(1), c^{*}=0.56(2), c=0.9 \mathrm{~g} \cdot \mathrm{dl}^{-1}(3)$, и пленок, полученных из растворов PЕI в NMP $(b): c=6(1)$, $c^{*}=14(2), c=20 \mathrm{~g} \cdot \mathrm{dl}^{-1}(3)$. Ось ординат $(\theta=0$ градусов) соответствует оси текстуры пленок - направлению с максимальным значением $\rho$.

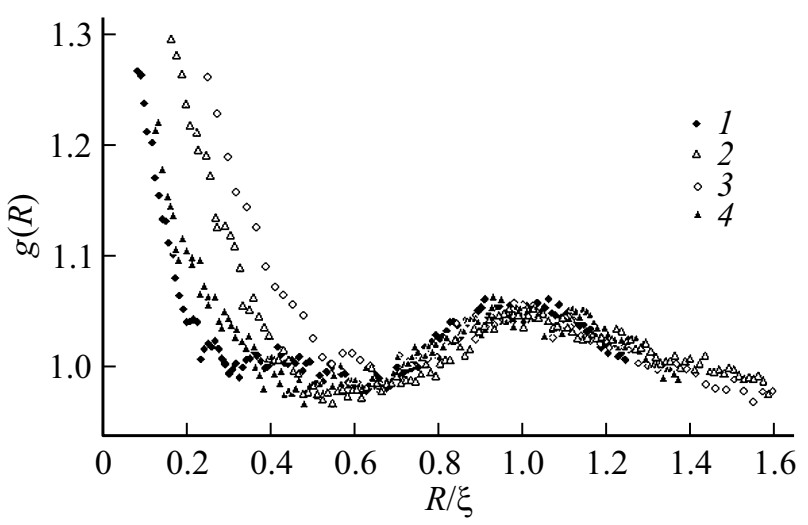

Рис. 4. Радиальные функции $g(R / \xi)$ распределения периодических микрофлуктуаций повышенной плотности на поверхности пленок, полученных: 1 - из раствора at-PS в Dek $\left(c=0.9 \mathrm{~g} \cdot \mathrm{dl}^{-1}\right), 2-$ из раствора at-PS в $\mathrm{Chl}\left(c=0.9 \mathrm{~g} \cdot \mathrm{dl}^{-1}\right)$, 3 - из раствора PЕI в NMP $\left(c=20 \mathrm{~g} \cdot \mathrm{dl}^{-1}\right), 4$ - из раствора PI в $\mathrm{Chl}\left(c=18 \mathrm{~g} \cdot \mathrm{dl}^{-1}\right)$.

с концентрацией полимера $\sim c^{*}$. Топологическая структура поверхности такой пленки обладает фрактальными свойствами и возникает вследствие самоорганизующегося поведения кластеров макромолекул в растворе. В данном случае наблюдается максимум разрывного 
напряжения образца в ряду всех изученных образцов пленок PEI [12].

На рис. 4 приведены функции $g(R)$ микрофлуктуаций повышенной плотности упаковки макромолекул на поверхности пленок, полученных из концентрированных растворов изученных полимеров. Функции демонстрируют общие для всех образцов периодические осцилляции плотности. Использование шкалы масштаба в безразмерном виде $(R / \xi)$ позволяет сравнить корреляционные функции и обосновать модель кластер-кластерной агрегации. Приведенные на рис. 4 функции $g(R)$ различаются между собой только по положению началь-
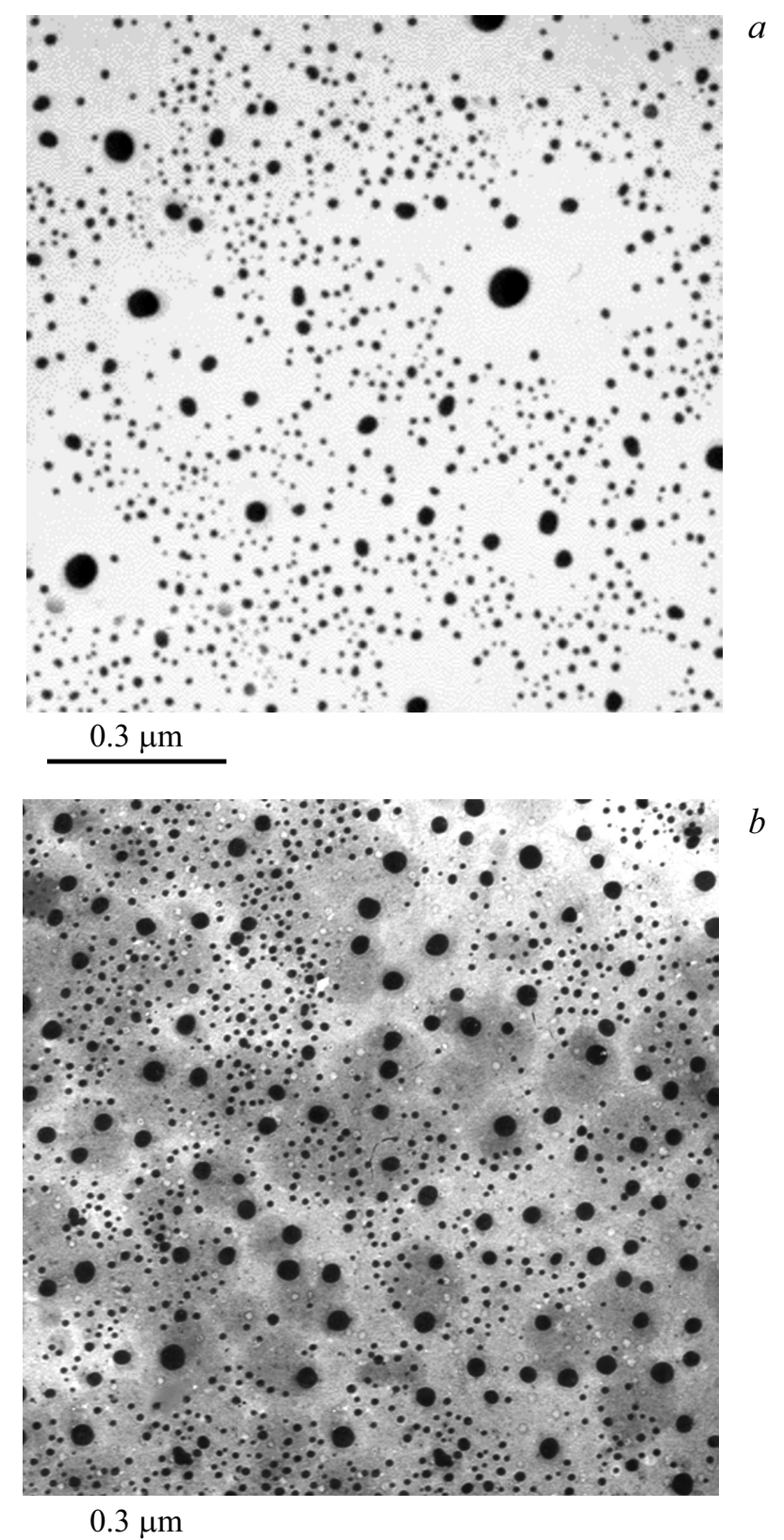

Рис. 5. Электронные микрофотографии декорированной золотом поверхности пленок PEI, полученных из растворов полимера в NMP при $c=20 \mathrm{~g} \cdot \mathrm{dl}^{-1}$ в отсутствии $(a)$ и при наличии добавки $\mathrm{C}_{60}(\sim 1$ mass.\% от PEI) $(b)$.

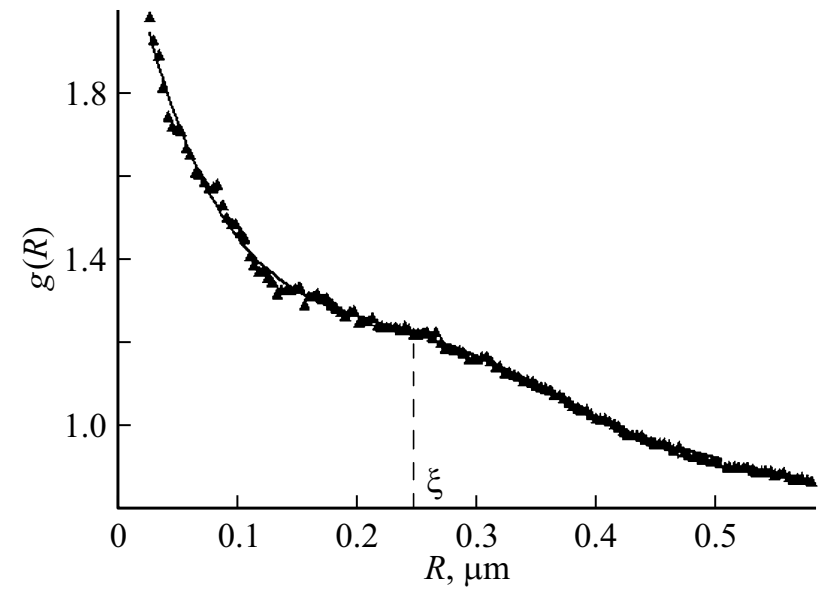

Рис. 6. Радиальная функция $g(R)$ распределения микрофлуктуаций повышенной плотности на поверхности фуллеренсодержащей пленки PEI.

ного участка, а в области максимума $(R / \xi=1)$ они полностью совпадают. Позиция $R$ границы начального участка, на котором наблюдается спад функций $g(R)$, близка к эффективному гидродинамическому радиусу кластеров в растворе [5,9]. Важно, что вид функций на масштабе $\sim \xi$ не зависит от химического состава и молекулярной массы полимера. Этот факт подтверждает единую модель кластер-кластерной агрегации с последующей универсальной самоорганизацией частиц при пленкообразовании.

Добавление в пленкообразующий раствор растворимых в нем низкомолекулярных веществ, молекулы которых способны формировать протяженные устойчивые кластеры, препятствует самоорганизации агрегатов макромолекул и, как следствие, образованию в полимерной пленке пространственно-модулированных микрофлуктуаций плотности. Об этом свидетельствует анализ топологической структуры поверхности пленки PEI, сформированной из концентрированного раствора полимера $\left(c=20 \mathrm{~g} \cdot \mathrm{dl}^{-1}\right)$ в присутствии фуллерена $\mathrm{C}_{60}$ в количестве $\sim 1$ mass.\% от PEI (рис. 5). Известно, что при растворении в NMP молекулы $\mathrm{C}_{60}$ агрегируют с образованием устойчивых кластеров, достигающих размера до $0.5 \mu \mathrm{m}$ [20]. Размер образующихся кластеров молекул $\mathrm{C}_{60}$ сопоставим с корреляционной длиной $\xi$ микрофлуктуаций плотности в пленке PEI (рис. 2, $b$, кривая 3). По этой причине накладываются пространственные ограничения на процессы кооперативной диффузии и взаимопроникновения кластеров макромолекул PEI при пленкообразовании.

На поверхности фуллеренсодержащей пленки PEI отсутствуют периодические пространственные осцилляции микрофлуктуаций повышенной плотности (рис. 6) в отличие от образца, не содержащего добавку $\mathrm{C}_{60}$ (рис. 2, $b$, кривая 3). Функция $g(R)$ с ростом величины масштаба немонотонно спадает, а при $R>\xi$ выполняется степенной закон падения: $g(R) \propto R^{-0.4}$ (рис. 6), свидетельствующий о фрактальной структуре бесконеч- 
ного кластера плотноупакованных макромолекул. Доля поверхности, занимаемая этим кластером в присутствии $\mathrm{C}_{60}$ составляет $\sim 0.3$ как и без фуллерена. Однако значение фрактальной размерности $D \sim 1.6 \pm 0.05$ в данном случае меньше, что является следствием уменьшения вероятности слипания кластеров макромолекул в растворе по сравнению с моделью ССА случайной кластер-кластерной агрегации.

\section{4. Заключение}

Процессы кооперативной диффузии, необратимой агрегации, а также взаимопроникновения макромолекул и кластеров в пленкообразующем растворе предопределяют особенности топологии микрофлуктуаций плотности в тонких аморфных полимерных пленках. Для изученных систем полимер-растворитель наблюдается общая тенденция: с ростом исходной концентрации $c$ растворов в пленках усиливаются эффекты микрофазового разделения. Эти эффекты выражаются в увеличении анизотропии, дальнего порядка и корреляционной длины $\xi$ флуктуаций плотности.

С точки зрения формирования характерной топологической структуры пленок важными являются два концентрационных режима их получения. Эти режимы отвечают условиям $c \sim c^{*}$ и $c>c^{*}$, где $c^{*}-$ пороговая концентрация раствора. Первый режим, соответственно, приводит к образованию в пленках фрактального бесконечного кластера плотноупакованных макромолекул, а второй режим трансформирует структуру этого кластера, создавая периодические пространственные осцилляции плотности.

По шкале параметра $c$ указанные режимы получения пленок соответствуют начальной и завершающей стадиям процесса самоорганизации кластеров макромолекул в растворе. Универсальный характер самоорганизации проявляется в том, что с ростом $c$ пространственные корреляции типа плотность-плотность в пленках на масштабе $\sim \xi$ перестают зависеть от химического состава и молекулярной массы полимера.

Топологическую структуру пленок можно регулировать введением в пленкообразующий раствор низкомолекулярных веществ, молекулы которых способны ассоциировать друг с другом и тем самым препятствовать самоорганизации агрегатов макромолекул.

\section{Конфликт интересов}

Автор заявляет об отсутствии конфликта интересов.

\section{Список литературы}

[1] I.W Hamley. Introduction to Block Copolymers in Developments. In: Block Copolymer Science and Technology / Ed. I.W. Hamley. John Wiley \& Sons. London (2004). P. 10-38.

[2] Д.В. Новиков, В.М. Светличный, А.А. Мартыненков. ФТТ 61, 1391 (2019).
[3] Б.А. Розенберг. Рос. хим. журн. XLV, 23 (2001).

[4] Д.В. Новиков, А.Н. Красовский, В.Н. Филиппов. ФТТ 56, 2246 (2014).

[5] Д.В. Новиков, А.Н. Красовский, Н.А. Осмоловская, В.И. Ефремов. ФТТ 49, 364 (2007).

[6] Д.В. Новиков, А.Н. Красовский. ФТТ 53, 2242 (2011).

[7] А.А. Тагер. Физикохимия полимеров. Химия, М. (1978). C.433.

[8] С.П. Папков. Студнеобразное состояние полимеров. Химия, М. (1974). С. 99.

[9] Д.В. Новиков, А.Н. Красовский, В.Н. Филиппов, Т.Е. Суханова, В.М. Светличный. ЖПХ 76, 1160 (2003).

[10] Д.В. Новиков. ФТТ 59, 1006 (2017).

[11] Д.В. Новиков, Т.Е. Суханова, В.М. Светличный, И.В. Гофман, А.И. Григорьев, А.Л. Диденко, Т.А. Маричева, В.В. Кудрявцев. Высокомолекуляр. соединения 43А, 655 (2001).

[12] Д.В. Новиков. Автореф. докт. дис. СПбГТИ, СПб. (2009). $40 \mathrm{c}$.

[13] О.В. Каллистов, И.Г. Силинская, Г.Б. Кузнецова, В.П. Склизкова, В.В. Кудрявцев, А.В. Сидорович, М.М. Котон. Высокомолекуляр. соединения 29Б, 67 (1987).

[14] H. Haken. Synergetics. Introduction and Advanced Topics. Springer-Verlag, Berlin-Heideiberg. (2004). 321 p.

[15] В.Л. Гиляров. ФТТ 47, 808 (2005).

[16] Д.В. Новиков, Г.К. Ельяшевич, В.К. Лаврентьев, И.С. Курындин, А. Anzlovar, V. Bukoshek. ФТТ 56, 390 (2014).

[17] J. Feder. Fractals. Plenum Press, N.Y., London (1988). 260 p.

[18] R. Jullien, M. Kolb, R. Botet. J. de Phys. 45, L211 (1984).

[19] Г.М. Павлов, А.С. Губарев, Г.Ф. Колбина, И.П. Коломиец, А.Л. Диденко, В.М. Светличный. Высокомолекуляр. соединения 59А, 150 (2017).

[20] T.V. Tropin, N. Jargalan, M.V. Avdeev, O.A. Kyzyma, D. Sangaa, V.L. Aksenov, R.A. Eremin. J. Mol. Liquids. 175, 4 (2012).

Редактор Д.В. Жуманов 